\title{
Modeling and Control for PEM Fuel Cell Stack System ${ }^{1}$
}

\author{
Jay T. Pukrushpan, Anna G. Stefanopoulou, Huei Peng \\ Automotive Research Center, University of Michigan, Ann Arbor \\ pukrushp@umich.edu, annastef@umich.edu, hpeng@umich.edu
}

\begin{abstract}
A nonlinear fuel cell system dynamic model that is suitable for control study is presented. The transient phenomena captured in the model include the flow characteristics and inertia dynamics of the compressor, the manifold filling dynamics, and consequently, the reactant partial pressures. Characterization of the Fuel Cell polarization curves based on time varying current, partial oxygen and hydrogen pressures, temperature, membrane hydration allows analysis and simulation of the transient fuel cell power generation. An observer based feedback and feedforward controller that manages the tradeoff between reduction of parasitic losses and fast fuel cell net power response during rapid current (load) demands is designed.
\end{abstract}

\section{Introduction}

Fuel cell stack systems are under intensive development by several manufacturers, with the Proton Exchange Membrane (PEM, also known as Polymer Electrolyte Membrane) Fuel Cells (FC) currently considered by many to be in a relatively more developed stage for ground vehicle applications. There are three major control subsystem loops in the fuel cell system that regulate the air/fuel supply, the water management and the heat management [1]. In this paper we concentrate on the air and direct hydrogen $\left(H_{2}\right)$ supply subsystems. In the air supply subsystem we control the compressor motor power (through voltage or current) in order to regulate (and replenish) the oxygen depleted from the FC cathode during power generation. This task needs to be achieved fast and efficiently to avoid degradation of the stack voltage and sluggish net power response [2]. Creating a control-oriented dynamic model of the overall system is an essential first step, not only for the understanding of the system behavior, but also for the development and design of model-based control methodologies.

Fuel cell (propulsion) system models in the literature are mostly steady-state models which are typically used for component sizing $[3,4,5]$, cumulative fuel consumption or hybridization studies [6], and forward-looking simulation models [7]. These models represent each component such as compressor, heat exchanger and fuel cell stack voltage as a static performance or efficiency map. The only dynamics considered is the vehicle inertia. The authors usually assume perfect conditions in the cathode (stoichiometry, pressure, humidity and stack temperature). Although the dynamic $\mathrm{FC}$ behavior is not included, these studies established a good basis for understanding the fuel cell vehicle integration. Few papers address the effects of transient variations

\footnotetext{
${ }^{1}$ Support is provided by the U.S. Army Center of Excellence for Automotive Research, Contract DAAE07-98-3-0022
}

in the fuel cell system performance. Excellent examples are the dominant but slow temperature effects on the stack efficiency $[8,9]$, and the effects of reformed hydrogen $H_{2}$ feed rates in the stack response $[10,11]$. Last but not least, the FC dynamic behavior due to changes in reactant flow is modeled in [12] and presented in [13]. The authors in [14] raise a lot of interesting issues associated with the dynamic interactions of the flow, heat, and water subsystems but did not provide a comprehensive set of equations for their study.

In this paper, the stack terminal voltage is modeled based on the FC load current and FC operating conditions, including cell temperature, air pressure, oxygen partial pressure and membrane humidity. The $\mathrm{FC}$ voltage is determined using a polarization curve based on the reversible cell voltage, activation losses, ohmic losses and concentration losses. Flow equations, mass and energy balance and electrochemical relations were used to create a lumped dynamic model of the FC cathode. Air pressure and humidity are calculated by balancing mass of air and water entering and leaving the FC stack, vapor carried by the air flow, oxygen consumed and water produced by chemical reaction. Thermodynamic principles are used to determine an average partial pressure of oxygen inside the cathode channel. Water content, both vapor and liquid states, stored inside fuel cell cathode are computed and used to represent the effect of membrane dehydration and fuel cell water flooding. The physical parameters are calibrated based on data reported in literature and the system is sized to represent the stack in the P2000 Ford experimental vehicle [2].

The model is used to analyze and design an air flow controller for the FC stack supercharging device that allows fast and robust air flow supply to the cathode. The controller needs to avoid the compressor stall and surge regions during large current steps (up and down, respectively). Another control difficulty arises even during small current demands. Namely, the power utilized by the supercharger is a parasitic loss for the FC stack. We show that minimizing these parasitic losses and providing fast air flow regulation are conflicting objectives. The conflict arises from the fact that the supercharger is using part of the stack power to accelerate. One way to resolve this conflict is to augment the FC system with an auxiliary battery or an ultracapacitor that can drive the auxiliary devices and can potentially buffer the FC from transient current demands. These additional components, however, will introduce complexity and additional weight that might not be necessary [15]. To judiciously decide about the system architecture and the component sizing we analyze the tradeoff between the two objectives using linear control theoretic techniques. We finally provide a controller and a calibration methodology for exploring all 
feasible responses.

\section{Nonlinear Fuel Cell Stack System Model}

A nonlinear dynamic model of the FC system is developed using electrochemical, thermodynamic and zero-dimensional fluid mechanics principles. We concentrate on the dynamical PEM-FC behavior associated with the reactant pressure and flow and we neglect the slower dynamics associated with temperature regulation and heat dissipation. We, thus, assume a well regulated averaged stack temperature throughout our modeling, analysis, and control design. We also assume that the inlet reactant flows in the cathode and anode can be humidified, heated and cooled in a consistent and rapid way. Although this assumption will not be always true, especially during fast transients, lack of experimental data makes it difficult to develop an accurate representation of dynamic coupling between temperature and humidity variations.

\subsection{Preliminaries}

The volumes associated with the $\mathrm{FC}$ system are shown in Figure 1. In this study, it is assumed that the multiple cathode and anode volumes of the multiple fuel cells in the stack are lumped together as a single stack cathode and anode volumes, with the values of $0.01 \mathrm{~m}^{3}$ and $0.005 \mathrm{~m}^{3}$, respectively. Pressurized hydrogen is supplied to the FC stack anode through a pressure regulator that to be discussed in Section 3. The anode supply and return manifold volumes are very small and the pure hydrogen flow allows us to lump all these volumes to one "anode" volume. We denote all the variables associated with the lumped anode volume with a subscript (an). Similarly, the cathode supply manifold $(\mathrm{sm})$ lumps all the volumes associated with pipes and connection between the compressor and the stack cathode (ca). The cathode supply manifold volume in the P2000 experimental vehicle is significant $\left(0.02 \mathrm{~m}^{3}\right)$ due to the large distance between the flow control device (located in the front of the vehicle) and the stack (located in the rear trunk of the vehicle). The cathode return manifold is small $\left(0.005 \mathrm{~m}^{3}\right)$ and represents lump volume of pipes downstream of the stack cathode .

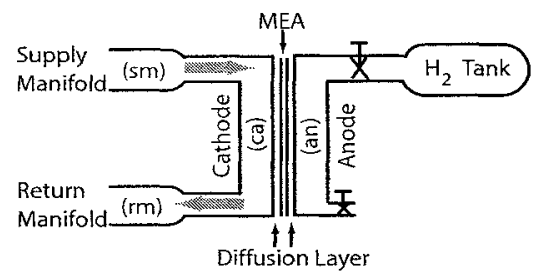

Figure 1: Volumes in fuel cell reactant supply system

Masses $(\mathrm{kg})$ are denoted with $m$, mass flows $(\mathrm{kg} / \mathrm{s})$ with $W$, pressure $(\mathrm{Pa}$ ) with $p$, power (Watts) with $P$, temperatures (K) with $T$, rotational speed ( $\mathrm{rad} / \mathrm{s})$ with $\omega$, current (A) with $I$, current density $\left(\mathrm{A} / \mathrm{cm}^{2}\right)$ with $i$, area $\left(\mathrm{cm}^{2}\right)$ with $A$, molar masses $(\mathrm{kg} / \mathrm{mol})$ with $\mathrm{M}$, volume $\left(\mathrm{m}^{3}\right)$ with $\mathrm{V}$, voltage (Volts) with $v$. The variables associated with vapor are denoted with a subscript $v$, oxygen with $\mathrm{O}_{2}$, nitrogen with $\mathrm{N}_{2}$, hydrogen with $\mathrm{H}_{2}$. The variables in specific volumes have as a second subscript the volume identifier ( $s m, c a, r m, a n)$.
The variables for the compressor or the compressor motor have $c p$ or $\mathrm{cm}$, respectively as their subscript. Similarly, the stack variables use $s t$, the individual fuel cells variables use $f c$, and the membrane variables use $m b r$ as their subscripts.

\subsection{State Space Representation}

The model contains nine states which are $m_{\mathrm{O}_{2}}$ mass of oxygen in the cathode $(\mathrm{kg}), m_{N_{2}}$ mass of nitrogen in the cathode $(\mathrm{kg}), m_{w, \mathrm{ca}}$ mass of water in the cathode $(\mathrm{kg}), m_{\mathrm{H}_{2}}$ mass of hydrogen in the anode $(\mathrm{kg}), m_{w, a n}$ mass of water in the anode $(\mathrm{kg}), \omega_{c p}$ compressor speed ( $\mathrm{rad} / \mathrm{sec}$ ), $p_{s m}$ supply manifold pressure (Pascal), $m_{s m}$ mass of air in the supply manifold ( $\mathrm{kg}$ ), $p_{r m}$ return manifold pressure (Pascal).

The principle of conservation of mass is used to obtain governing equations for oxygen, nitrogen and water mass inside the cathode volume:

$$
\begin{aligned}
\frac{d m_{\mathrm{O}_{2}}}{d t} & =W_{\mathrm{O}_{2}, \text { in }}-W_{\mathrm{O}_{2}, \text { out }}-W_{\mathrm{O}_{2}, \text { ract }} \\
\frac{d m_{N_{2}}}{d t} & =W_{N_{2}, \text { in }}-W_{N_{2}, \text { out }} \\
\frac{d m_{w, \text { } a}}{d t} & =W_{v, c a, \text { in }}-W_{v, \text { ca,out }}+W_{v, \text { gen }}+W_{v, m b r}(3)
\end{aligned}
$$

Note that the rate of change of the mass of water inside the cathode, $m_{w, c a}$, depends solely on the summation of vapor flows, because it is assumed that the liquid water does not leave the stack and evaporates into the cathode gas if cathode humidity drops below $100 \%$. The mass of water is in vapor form until the relative humidity of the gas exceeds saturation $(100 \%)$, the point at which vapor condenses into liquid water. Note also that the partial pressures for the oxygen, nitrogen and vapor in the cathode are algebraic functions of the states through the ideal gas law and the psychrometric laws since the cathode temperature is considered fixed at $T_{s t}=353 \mathrm{~K}$.

Similarly, governing equations for hydrogen and water in the anode can be written as

$$
\begin{aligned}
\frac{d m_{H_{2}}}{d t} & =W_{H_{2}, i n}-W_{H_{2}, \text { purge }}-W_{H_{2}, \text { ract }} \\
\frac{d m_{w, a n}}{d t} & =W_{v, a n, i n}-W_{v, \text { an }, \text { out }}-W_{v, m b r}
\end{aligned}
$$

The dynamics of air supercharging device is governed by the compressor inertia, $J_{c p}\left(5 \times 10^{-5} \mathrm{~kg} / \mathrm{m}^{2}\right)$,

$$
J_{c p} \frac{d \omega_{c p}}{d t}=\frac{1}{\omega_{c p}}\left(P_{c m}-P_{c p}\right)
$$

where $P_{c m}$ and $P_{c p}$ are the power supplied to the compressor motor and the compressor power load, respectively. A static nonlinear motor equation is used to model the $14 \mathrm{~kW} \max$ power compressor motor. The rate of change of mass inside the manifold, $m_{s m}$, is governed by the mass conservation principle and the rate of change of supply manifold pressure, $p_{s m}$, is governed by the energy conservation principle:

$$
\begin{aligned}
\frac{d m_{s m}}{d t} & =W_{c p}-W_{c a, i n} \\
\frac{d p_{s m}}{d t} & =\frac{\gamma R_{a}}{V_{s m}}\left(W_{c p} T_{c p, o u t}-W_{c a, i n} T_{s m}\right)
\end{aligned}
$$

where $R_{a}$ is the air gas constant, $V_{s m}$ is the manifold volume and $T_{s m}$ is the supply manifold gas temperature. The exit 
temperature from the compressor, $T_{c p, o v t}$ is typically higher than the desired air inlet temperature. The return manifold pressure, $p_{r m}$, is governed by the mass conservation and the ideal gas law through isothermic assumptions.

$$
\frac{d p_{r m}}{d t}=\frac{R_{a} T_{r m}}{V_{r m}}\left(W_{c a, o u t}-W_{r m, o u t}\right)
$$

where $V_{r m}$ and $T_{r m}$ are return manifold volume and gas temperature, respectively.

\section{Reactant Flow Rates}

The compressor air mass flow rate, $W_{c p}$, is determined, through a compressor flow map (Allied Signal [16]) which is modeled by the nonlinear curve fitting method described in [17]. The thermodynamic equations are used to calculate exit air temperature, $T_{c p, o u t}$, and required compressor power, $P_{c p}$. The air flow rate in and out $\left(W_{c a, i n}\right.$ in (7) and $W_{c a, \text { out }}$ in (9)) of the cathode are functions of the difference between the pressure of the gas upstream and downstream, and are approximated by a linear nozzle equation $W=k\left(p_{1}-p_{2}\right)$. The flow rates of each element $\left(\mathrm{O}_{2}, \mathrm{~N}_{2}\right.$, vapor) in (1)-(3) are determined using thermodynamic and psychrometric properties of the gas upstream. The return manifold exit flow rate, $W_{r m, o u t}$, is calculated using nonlinear nozzle equation to account for large pressure drops.

The rates of oxygen reacted, $W_{\mathrm{O}_{2} \text {, reacted }}$ in equation (1), hydrogen reacted, $W_{\mathrm{H}_{2}}$, reacted $(4)$, and water generated $W_{v, \text { gen }}$ (3), in the fuel cell reaction are calculated from the stack current, $I_{s t}$, using the electrochemical equations

$W_{\mathrm{O}_{2}, \text { ract }}=M_{\mathrm{O}_{2}} \frac{n I_{s t}}{4 F}, W_{\mathrm{H}_{2}, \text { ract }}=M_{\mathrm{H}_{2}} \frac{n I_{s t}}{2 F}, W_{v, g e n}=M_{v} \frac{n I_{s t}}{2 F}$

where $n$ is the number of cells in the stack, $F$ is the Faraday number (96485 coulombs) and $M_{\mathrm{O}_{2}}, M_{\mathrm{H}_{2}}$ and $M_{v}$ are the molar mass of oxygen, hydrogen and vapor, respectively.

The mass flow of vapor across the membrane, $W_{v, m b r}$, is calculated using mass transport principles and membrane properties given in [18].

$$
W_{v, m b r}=M_{v} A_{f c} n\left(n_{d} \frac{i}{F}-D_{w} \frac{\left(c_{v, c a}-c_{v, a n}\right)}{t_{m}}\right)
$$

where $A_{f c}$ is the active area of the fuel cell $\left(280 \mathrm{~cm}^{2}\right), n_{d}$ is electro-osmotic coefficient, $D_{w}$ is diffusion coefficient, $t_{m}$ is membrane thickness, and $c$ is the membrane water concentration which is a function of relative humidity in the anode and cathode. The fuel cell current density, $i$, is defined as current per active area. The detailed calculations of $c, n_{d}$ and $D_{w}$ along with the calculation of membrane humidity are given in [19]. In this paper, we focus on the effect of oxygen supply system, thus we assume $100 \%$ humidified membrane.

When current is drawn from the fuel cell, the oxygen in the cathode is depleted. We define the instantaneous oxygen excess ratio $\left(\lambda_{\mathrm{O}_{2}}\right): \lambda_{\mathrm{O}_{2}}=W_{\mathrm{O}_{2}, \text { in }} / W_{\mathrm{O}_{2} \text {,ract }}$. The anode inlet flow rate, $W_{a n, i n}$, is regulated to maintain a small pressure difference across the membrane. This can be achieved by using a high-gain proportional control with reference signal from the supply manifold pressure sensor.

\section{Fuel Cell Power Generation}

Typically, the FC characteristics are given in the form of a polarization curve, which is the plot of $\mathrm{FC}$ voltage versus current density. The current density, $i$, is defined as current per active area, $i=I_{s t} / A_{f c}$. Since fuel cells are connected in series to form the stack, the total stack voltage is $v_{s t}=$ $n \cdot v_{c e l l}$ and the stack power is $P_{s t}=v_{s t} \cdot I_{s t}$. Part of the stack power is used to drive the compressor motor. Therefore, the net power, $P_{n e t}=P_{s t}-P_{c m}$.

The FC polarization curve is a function of cathode pressure, reactant partial pressures, $\mathrm{FC}$ temperature and membrane humidity. The FC voltage is calculated by subtracting the fuel cell losses or overvoltages from the fuel cell open circuit voltage, $E$, i.e. $v_{f c}=E-v_{a c t}-v_{o h m}-v_{c o n c}$. The open circuit voltage is governed by the chemical potential [20]. The activation overvoltage, $v_{a c t}$, ohmic overvoltage, $v_{o h m}$, and concentration overvoltage, $v_{\text {conc }}$, each affects a different region in the polarization as shown in Figure 2 and is defined as

$$
\begin{aligned}
v_{a c t} & =v_{0}+v_{a}\left(1-e^{-c_{1} i}\right) \\
v_{o h m} & =i \cdot r_{o h m}=i \frac{t_{m}}{\sigma_{m}} \\
v_{\text {conc }} & =i\left(c_{2} \frac{i}{i_{\max }}\right)^{c_{3}}
\end{aligned}
$$

where membrane conductivity, $\sigma_{m}$, is a function of membrane humidity and fuel cell temperature, $T_{f c}$ :

$$
\sigma_{m}=b_{1} \exp \left(b_{2}\left(\frac{1}{303}-\frac{1}{T_{f c}}\right)\right)
$$

where $b_{1}$ is a parameter heavily depends on membrane humidity. The coefficient values published in the literature are used for $t_{m}$ and $b_{1}$ in the expression (12) and (14). However, the value of $b_{2}$ is modified from the one given in [18] to match our PEM stack experimental data. The coefficients in the expression (11) and (13) are functions of temperature, pressure and oxygen partial pressures. The $\mathrm{FC}$ vehicle data are collected while the FC was controlled for steady-state $\lambda_{\mathrm{O}_{2}}=2$ and $100 \%$ cathode gas relative humidity. The pressure data is therefore translated to oxygen partial pressure, $p_{\mathrm{O}_{2}}$, and vapor saturation pressure, $p_{\text {sat }}$, which is a function of fuel cell temperature, $T_{f c}$. The fitted polarization curves versus experiment data are shown in Figure 2. The regression results are

$$
\begin{aligned}
& v_{0}=0.28-8.5 \times 10^{-4}\left(T_{f c}-298\right) \\
& +4.3 \times 10^{-5} T_{f c}\left[\ln \left(\frac{p_{c a}-p_{\text {sat }}}{1.01325}\right)+\frac{1}{2} \ln \left(\frac{0.12\left(p_{c a}-p_{\text {sat }}\right)}{1.01325}\right)\right] \\
& v_{a}=\left(-1.62 \times 10^{-5} T_{f c}-1.62 \times 10^{-2}\right) p_{x}^{2} \\
& +\left(1.8 \times 10^{-4} T_{f c}-0.17\right) p_{x}+\left(-5.8 \times 10^{-4} T_{f c}+0.57\right) \\
& c_{2}=\left\{\begin{array}{c}
\left(7.16 \times 10^{-4} T_{f c}-0.62\right) p_{x} \\
+\left(-1.45 \times 10^{-3} T_{f c}+1.68\right) \text { for } p_{x}<2 \mathrm{~atm} \\
\left(8.7 \times 10^{-5} T_{f c}-0.068\right) p_{x} \\
+\left(-1.6 \times 10^{-4} T_{f c}+0.54\right) \text { for } p_{x} \geq 2 \mathrm{~atm}
\end{array}\right. \\
& c_{1}=10 \quad i_{\max }=2.2 \quad c_{3}=2
\end{aligned}
$$

where $p_{x}=\left(\frac{P_{2}}{0.12}+p_{s a t}\right)$ and $T_{f c}$ is expressed in Kelvin and $p_{c a}$ and $p_{\mathrm{O}_{2}}$ are expressed in bar. 


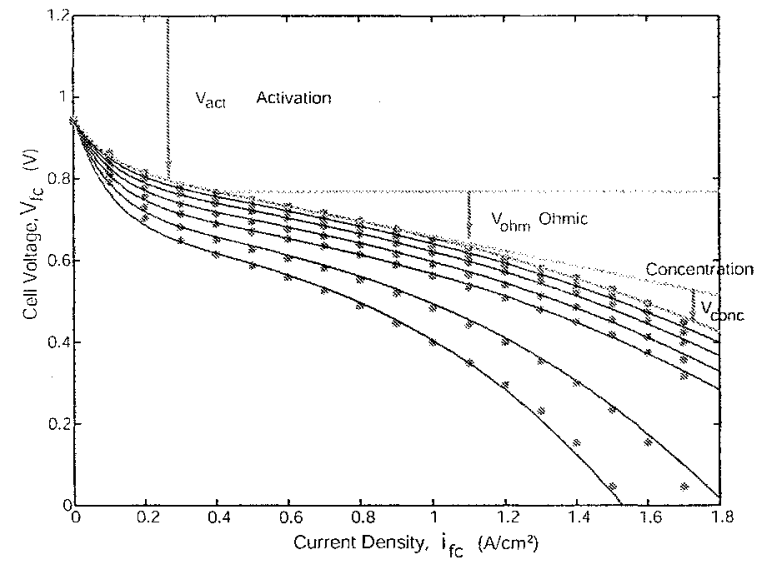

Figure 2: Fuel cell polarization curve

High $\lambda_{O_{2}}$, and thus high oxygen partial pressure, improves $P_{s t}$ and $P_{\text {net }}$. After an optimum $\lambda_{O_{2}}$ level, further increase will cause excessive increase of $P_{c m}$ and thus deteriorative effects on $P_{\text {net }}$. Using the model we plot of $\lambda_{O_{2}}$ and $P_{\text {net }}$ for different $I_{s t}$ as shown in Figure 3 . It can be seen that the highest net power is achieved at an oxygen excess ratio of 2 for the selected supercharger devices.

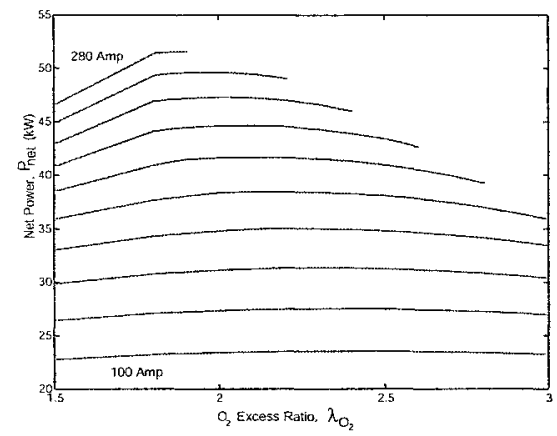

Figure 3: System net power at different stack current and oxygen excess ratio

\section{Control Problem Formulation}

For hydrogen/air PEM fuel cells, the required air flow is indicated by the desired oxygen excess ratio, $\lambda_{\mathrm{O}_{2}}^{\text {des }}=2$. Generating rapid increase in air flow, however, requires a large amount of power drawn by the compressor motor, thus increasing parasitic loss to the FC system and affecting the system net power. The combined control design objective is to manipulate the compressor motor input voltage, $v_{c m}$, in order to maintain $\lambda_{\mathrm{O}_{2}}=2$ and achieve the desired $\mathrm{FC}$ system net power, $P_{\text {net, }, e f}$. The desired net power can be translated into required stack current assuming proper operating conditions: $P_{n e t}^{r e f}=f_{P_{n e t}}\left(I_{s t}\right)$. The current $I_{s t}=f_{P_{n e t}^{-1}}^{-1}\left(P_{n e t}^{r e f}\right)$ is then considered as an external input to the system. The resulting control problem is defined as follows:

$$
\begin{array}{rlrl}
\dot{x} & =f(x, u, w) & & \text { State Equations } \\
y & =\left[W_{c p}, p_{s m}, v_{s t}\right]^{T}=h_{y}(x, u, w) & \text { Measurements } \\
z & =\left[P_{n e t}, \lambda_{O_{2}}\right]^{T}=h_{z}(x, u, w) & & \text { Performance Var. } \\
u & =v_{c m} & & \text { Control Input } \\
w & =I_{s t} & & \text { External Input }
\end{array}
$$

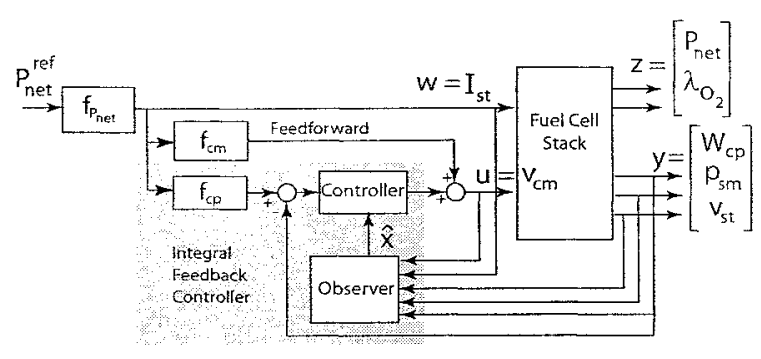

Figure 4: Control Architecture

Feedforward control algorithm can be used to control $v_{c m}$ based on the current drawn from the fuel cell stack as shown in Figure 4. For a specific ambient condition, the required air flow can be calculated from the stack current, i.e. $W_{c p}^{r e f}=$ $f_{c p}\left(I_{s t}\right)$. The inversion of compressor and compressor motor maps is used to find $v_{c m}^{r e f}$ that gives the desired air flow, $W_{c p}^{r e f}$, i.e. $v_{c m}^{r e f}=f_{c m}\left(I_{s t}\right)$. The response of the feedforward control system is shown as the dotted line in Figure 5.

The relation $W_{c p}^{r e f}=f_{c p}\left(I_{s t}\right)$ is an analytical function based on electrochemical and thermodynamic principles. Besides the stack current, the function depends on ambient air conditions, which include pressure, temperature and humidity. Knowing the air condition, $W_{c p}^{r e f}$ can be accurately calculated. However, the accuracy of mapping $v_{\mathrm{cm}}^{r e f}=f_{c m}\left(I_{s t}\right)$ is sensitive to device aging. Furthermore, determining the $f_{c m}$ map involves inversion of the nonlinear compressor and motor characteristics which cannot be formulated analytically. Moreover, obtaining the map $f_{c m}$ that covers all environment conditions is difficult for an experimental fuel cell systems. In order to increase the controller robustness against uncertainty in ambient conditions and device aging, feedback control is added as shown in Figure 4 .

\section{Feedback Control Design}

The nonlinear model is linearized around a nominal point of $40 \mathrm{~kW}$ net power. The coefficients in equation (10), defined by [18], results in a fully (vapor) saturated cathode. This, together with our assumption that the membrane is fully humidified, causes the state $m_{w, c a}$ to be unobservable from the system output. Note here that our model does not capture the effects of flooding on the FC performance. Therefore, the linearization results in a linear system with 8 states: $x=\left[m_{\mathrm{O}_{2}}, m_{H_{2}}, m_{N_{2}}, \omega_{c p}, p_{s m}, m_{w, a n}, m_{s m}, p_{r m}\right]^{T}$. An additional integrator state, $q$, on compressor flow rate is added to the linear system to ensure zero steady state error:

$$
\dot{q}=W_{c p}-W_{c p}^{r e f}
$$

The amount of required air flow however depends on stack current and temperature, pressure and humidity of the air as describe above. The control input, $v_{c m}$, becomes

$$
v_{c m}=-K_{f b} \Delta \hat{x}-K_{I} q+v_{c m}^{r e f}\left(I_{s t}\right)
$$

where $K_{f b}$ is the feedback proportional gain, $K_{I}$ is the integral gain and $\hat{x}$ is the state estimates. A state observer is designed based on the linear model. The linear quadratic (LQ) optimal control method is used to design the state feedback controller gain $K_{f b}$ and $K_{I}$ and the state estimator gain $L$. The linear responses for different control gains are shown in 
Figure 5. The tradeoff between $P_{\text {net }}$ and $\lambda_{\mathrm{O}_{2}}$ is evident during transients. A large $v_{c m}$ improves the response of $\lambda_{O_{2}}$. However, since the power used in the compressor is directly drawn from the stack power, there is a non-minimum phase relation between input $v_{c m}$ and output $P_{n e t}$. Therefore, a large value of $v_{c m}$ results in an initial inverse response of $P_{\text {net }}$ that lowers the positive response of $P_{\text {net }}$ gained by a step change in stack current, $I_{s t}$, as shown in Figure 5. A small value of $v_{c m}$ results in faster rise time of $P_{n e t}$ but longer settling time due to slow $\lambda_{\mathrm{O}_{2}}$ response causes by the small control input.

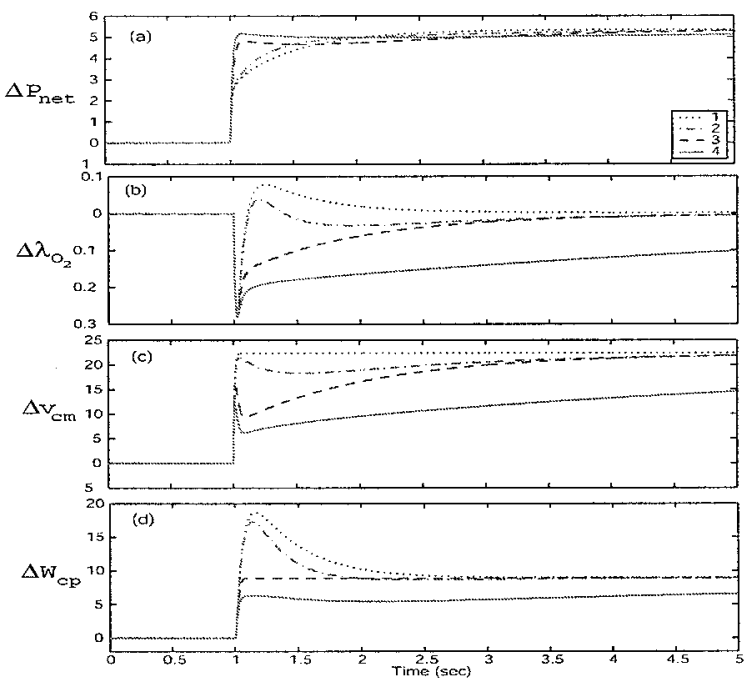

Figure 5: Linear system response: 1 - feedforward 234 feedback with different gain.

We design a low gain feedback controller that contributes very little to the feedforward $v_{c m}$ command unless there is an error in the feedforward maps (change in ambient conditions or compressor/motor aging, for example). This feedback design guarantee robustness and allows flexibility in shaping the system power response. This flexibility is typically achieved with add-hoc feedforward lead or lag compensation of the static $f_{c p}$ map [21]. Apart from begin heuristic, this uncertain approach is also sensitive to uncertainty in plant dynamics due to the underlying open loop cancellations. Our approach, which is to use model-based output feedback control, considers the dynamics of the system and dynamically adjusts the control signal based on measurements. This provides a systematic and robust methodology for achieving a reasonable tradeoff.

\section{Nonlinear Simulation Results}

The results using the nonlinear model under a series of step in net power from $25 \mathrm{~kW}$ to $55 \mathrm{~kW}$ are shown in Figures 69. The series of step in net power is converted to the stack current input as shown in Figure 6 (a). The compressor motor input calculated using the feedforward+feedback control described in the previous section is shown in Figure 6 (b). Good transient response of system net power and fast and accurate response of oxygen excess ratio are achieved as shown in Figure $6(\mathrm{~d})$ and (e). The stack voltage (Figure 7 (a)) is a function of stack current and oxygen partial pressure (Figure 7 (b)). Figure 7 (c) illustrates the performance of the anode pressure as it is regulated by the proportional feedback control law to follow the cathode pressure. The dynamic transitions between different compressor flow and pressure conditions are shown on the compressor map in Figure 8 and the dynamic fuel cell polarization is illustrated in Figure 9 .

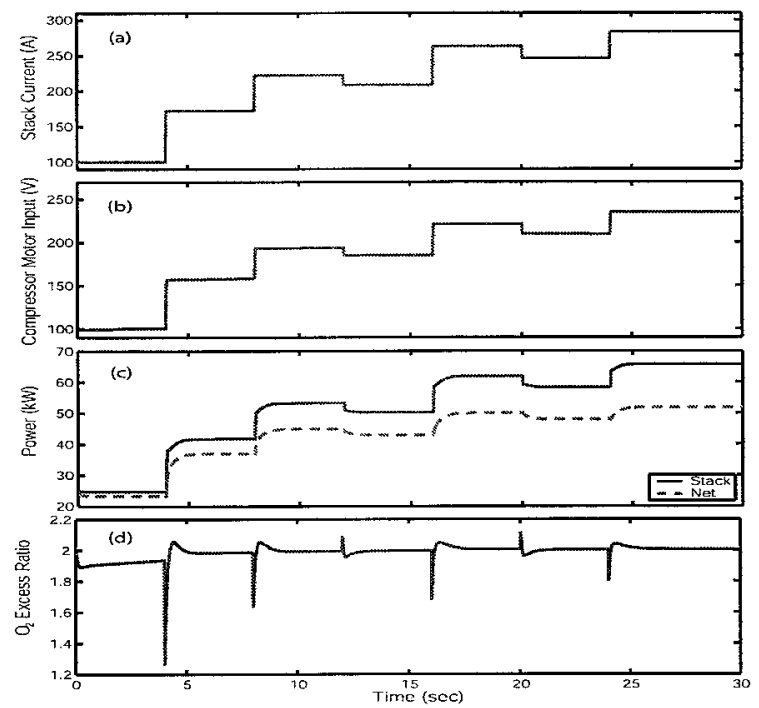

Figure 6: Simulation results of the nonlinear model: inputs and performance outputs

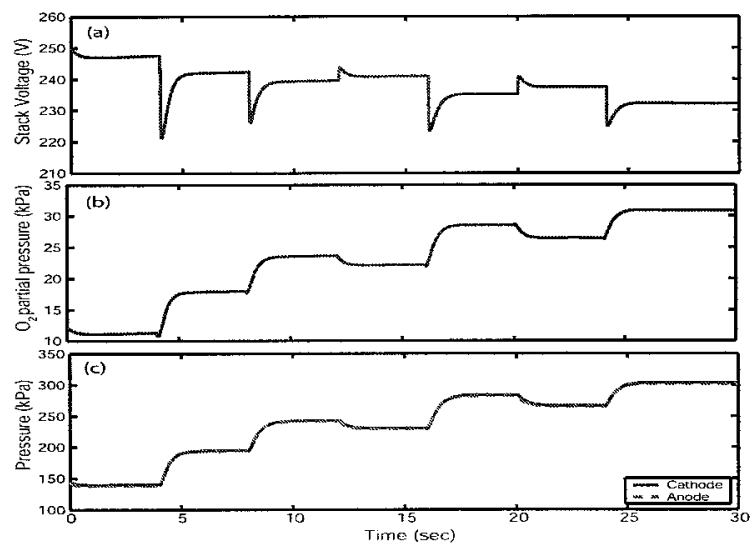

Figure 7: Simulation results of the nonlinear model: stack variables

\section{Conclusions}

Models of the main components of a control-oriented fuel cell system model were developed and the air flow control problem was presented. The transient phenomena, flow characteristics, and inertia dynamics of the compressor, manifold dynamics and reactant partial pressures are captured. The model, although not fully validated, captures the intrinsic breathing dynamics of a pressurized fuel cell stack.

A combination of a nonlinear feedforward and linear feedback controller is designed to regulate the excess oxygen ratio in the cathode during step changes in FC current demand. The feedback controller provides robustness through 


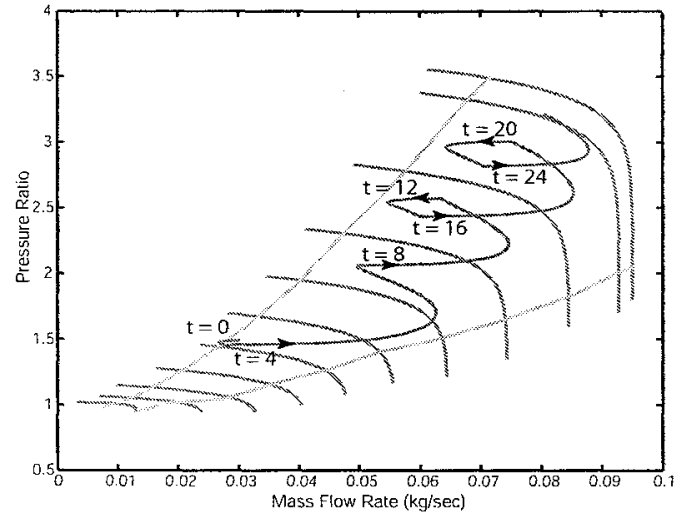

Figure 8: Compressor response on the compressor map

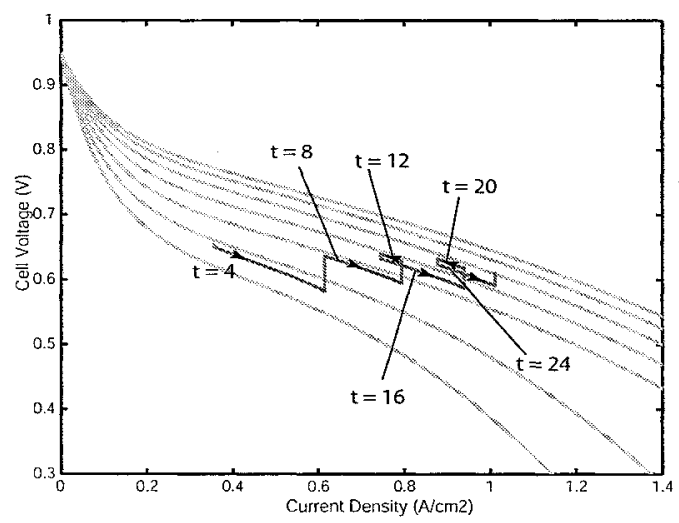

Figure 9: Fuel cell response on the fuel cell polarization map

the integration of the error between the desired and the measured compressor air flow. It also provides a means for calibrating the transient FC net power response and avoiding harmful compressor motor voltage command that can result in stall or surge. Moreover, we clarify the origins of the tradeoff between air flow control and system net power. Our analysis suggests a multivariable control architecture where the power conditioning unit of the fuel cell and the traction motor controller coordinate for better performance.

\section{Acknowledgment}

This research is supported by the U.S. Army Tank Automotive Research, Development and Engineering Center under the contract DAAE07-98-C-R-L008. The authors thank Herb Dobbs and Erik Kallio at the US Army TankAutomotive and Armaments Command and Woong-Chul Yang and James Adams at Ford Motor Company for their advice and encouragement.

\section{References}

[1] J.A. Adams, W-C Yang, K.A. Oglesby, and K.D. Osborne, "The development of Ford's P2000 fuel cell vehicle" SAE Paper 2000-01-1061.

[2] W-C Yang, B. Bates, N. Fletcher, and R. Pow, "Control challenges and methodologies in fuel cell vehicle development," SAE Paper 98C054.

[3] F. Barbir, B. Balasubramanian, and J. Neutzler, "Tradeoff design analysis of operating pressure and temperature in PEM fuel cell systems," Proceedings of the ASME Advanced Energy Systems Division, vol. 39, pp. 305-315, 1999.

[4] D.D. Boettner, G. Paganelli, Y.G. Guezennec, G. Rizzoni, and M.J. Moran, "Component power sizing and limits of operation for proton exchange membrane (PEM) fuel cell/battery hybrid automotive applications," Proceedings of 2001 ASME International Mechanical Engineering Congress and Exposition, 2001.

[5] D.J. Friedman, A. Egghert, P. Badrinarayanan, and J. Cunningham, "Balancing stack, air supply and water/thermal management demands for an indirect methanol PEM fuel cell system," SAE Paper 2001-01-0535.

[6] S. Akella, N. Sivashankar, and S. Gopalswamy, "Modelbased systems analysis of a hybrid fuel cell vehicle configuration," Proceedings of 2001 American Control Conference, 2001.

[7] L. Guzzella and A. Amstutz, "CAE tools for quasi-static modeling and optimization of hybrid powertrains," IEEE Transactions on Vehicular Technology, vol. 48, no. 6, pp. 1762-1769, 1999.

[8] W. Turner, M. Parten, D. Vines, J. Jones, and T. Maxwell "Modeling a PEM fuel cell for use in a hybrid electric vehicle," Proceedings of the 1999 IEEE 49th Vehicular Technology Conference, vol. 2, pp. 1385-1388, 1999.

[9] D.D. Boettner, G. Paganelli, Y.G. Guezennec, G. Rizzoni, and M.J. Moran, "Proton exchange membrane (PEM) fuel cell system model for automotive vehicle simulation and control," Proceedings of 2001 ASME International Mechanical Engineering Congress and Exposition, 2001.

[10] H.K. Geyer, R.K. Ahluwalia, and R. Kumar, "Dynamic response of steam-reformed, methanol-fueled, polymer electrolyte fuel cell systems," Proceedings of the Intersociety Energy Conversion Engineering Conference, vol. 2, pp. 1101-1106, 1996.

[11] K-H Hauer, D.J. Friedmann, R.M. Moore, S. Ramaswamy, A. Eggert, and P. Badrinarayana, "Dynamic response of an indirect-methanol fuel cell vehicle," SAE Paper 2000-01-0370.

[12] J. Padulles, G.W. Ault, C.A. Smith, and J.R. McDonald, "Fuel cell plant dynamic modelling for power systems simulation," Proceedings of 34 th universities power engineering conference, vol. 34, no. 1, pp. 21-25, 1999.

[13] L. Guzzella, "Control oriented modelling of fuel-cell based vehicles," Presentation in NSF Workshop on the Integration of Modeling and Control for Automotive Systems, 1999.

[14] S. Pischinger, C. Schönfelder, W. Bornschever, H. Kindl, and A. Wiartalla, "Integrated air supply and humidification concepts for fuel cell systems," SAE Paper 2001-01-0233.

[15] K. Rajashekara, "Propulsion system strategies for fuel cell vehicles," SAE Paper 2000-01-0369.

[16] J.M. Cunningham, M.A Hoffman, R.M Moore, and D.J. Friedman, "Requirements for a flexible and realistic air supply model for incorporation into a fuel cell vehicle (FCV) system simulation," SAE Paper 1999-01-2912.

[17] P. Moraal and I. Kolmanovsky, "Turbocharger modeling for automotive control applications," SAE Paper 1999-01-0908.

[18] T.E. Springer, T.A. Zawodzinski, and S. Gottesfeld, "Polymer electrolyte fuel cell model," Journal of Electrochemical Society, vol. 138, no. 8, pp. 2334-2342, 1991.

[19] J.T. Pukrushpan, H. Peng, and A.G. Stefanopoulou, "Simulation and analysis of transient fuel cell system performance based on a dynamic reactant flow model," submitted to the ASME International Mechanical Engineering Congress \& Exposition, 2002.

[20] J.C. Amphlett, R.M. Baumert, R.F. Mann, B.A. Peppley, and P.R. Roberge, "Performance modeling of the Ballard Mark IV solid polymer electrolyte fuel cell," Journal of Electrochemical Society, vol. 142, no. 1, pp. 9-15, 1995.

[21] W.E. Mufford and D.G. Strasky, "Power control system for a fuel cell powered vehicle," United States Patents 5,991,670, 1999. 